\title{
DO WE SEE WORD ORDER PATTERNS FROM SILENT GESTURE STUDIES IN A NEW NATURAL LANGUAGE?
}

\author{
MOLLY FLAHERTY*1 ${ }^{*}$, MARIEKE SCHOUWSTRA ${ }^{1}$, SUSAN GOLDIN-MEADOW ${ }^{2}$ \\ *Molly Flaherty: molly.flaherty@ed.ac.uk \\ ${ }^{1}$ Centre for Language Evolution, University of Edinburgh, Edinburgh, UK \\ ${ }^{2}$ Department of Psychology, The University of Chicago, Chicago, USA
}

Typological analysis clearly shows that the world's languages are not evenly distributed among all logically possible patterns. Of the six possible orderings of Subject (S), Object (O), and Verb (V), SOV and SVO orders are vastly overrepresented in the world's languages. Studies on the emergence of word order regularities in silent gesture by hearing non-signers (e.g., Goldin-Meadow, et al., 2008; Gibson et al., 2013) overwhelmingly find evidence for SOV ordering. Based on this type of evidence, it has been proposed that SOV ordering is the most basic ordering from which all other orders emerged. However, semantic properties of the meanings to be conveyed also influence word order in silent gesture. For instance, for intensional events (in which the object is possibly non-existent or dependent on the action; e.g., 'man thinks of guitar', 'woman builds house') a cross-linguistic preference for SVO was found (Schouwstra \& de Swart, 2014). Recent work finds that meaning-dependent word order patterns typical of silent gesture disappear under the influence of interaction (Christensen et al., 2016) and cultural transmission (Schouwstra et al., 2016), in favor of more consistent word order usage. However, in these studies, word order usage never becomes completely regular.

Here we investigate whether traces of the SOV/SVO pattern found in silent gesture can be observed in a new natural language: Nicaraguan Sign Language. This sign language, one of the youngest languages known to science, was born in the late 1970s with the founding of a new school for special education. Though instruction was in Spanish, students soon began to communicate with one another manually. As succeeding cohorts of students learn NSL, the language itself is changing rapidly. Though somewhat variable, NSL word order is strongly verb-final and predominantly SOV (Flaherty, 2014). However, these data are based exclusively on analysis of extensional events. If NSL word order is also influenced by semantic properties of the utterance's intended meaning, we would expect to see deviation from this SOV patterning. 
Participants viewed a series of events depicting eight extensional events (i.e. woman pop bubble) and eight intensional events (i.e. woman blow bubble) involving the same object. Participants were asked to describe what they saw to a peer. Twenty-six NSL signers participated. All signers were exposed to NSL before age 7, upon school entry between the early 1980s and early 2000s.

When we analyzed SOV and SVO strings (which accounted for only $39 \%$ of strings with 1 verb and 2 arguments), we did not observe the pattern typical of silent gesture: SOV was dominant for both extensional and intensional events, and very few SVO strings were observed (13 total, 10 for intensional events). NSL's preference for verb-finalness (Flaherty, 2014) may not have allowed the SVO pattern to emerge. However, NSL signers tend to provide more detail than silent gesturers. As a result, many NSL strings were longer than strings observed in silent gesture. When we took into account all strings (including those with several verbs) and asked whether the Object preceded or followed target the

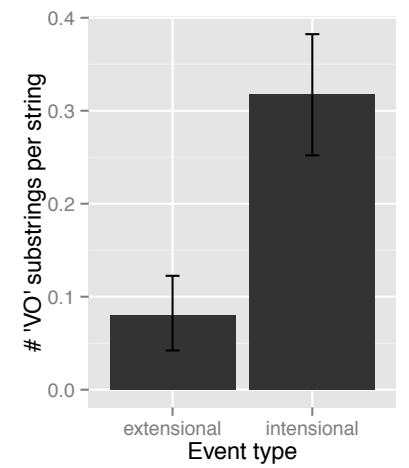

Figure 1. Proportion of extensional and intensional events containing 'Verb-Object' substrings. Verb, we found more utterances with VO substrings (as opposed to OV) for intensional events than for extensional events (Fig 1). A logit mixed effects regression (with event type as fixed effect and random effects for item and signer) confirmed that strings containing $\mathrm{VO}$ were uncommon for extensional events $(\beta=-2.9$, $S E=0.40, p<0.001)$, but significantly more likely for intensional events $(\beta=1.8, S E=0.45$, $p<0.001)$. Thus, objects of intensional verbs are more likely to follow those verbs than are objects of extensionals not only in silent gesture, but also in an emerging sign language.

In this study, we find evidence for labdocumented word order preferences in an emergent natural language: objects precede verbs for extensional events, but follow verbs for intensional events. However, this word order pattern is manifested differently in Nicaraguan Sign because it interacts with NSL's language-internal constraint for verb finalness. A combination of lab and fieldbased methodologies made this finding possible: without laboratory results, we would not have looked at a wider semantic range of events in the field; without field data, we would not have discovered the interaction between VO ordering preference and existing natural language constraints.

\section{Acknowledgements}

Supported by a Royal Society NIF (MF), a British Academy Postdoctoral Fellowship (MS), and NIH R01-DC000491 (SGM). 


\section{References}

Christensen, P., Fusaroli, R., Tylén, K. (2016). Environmental constraints shaping constituent order in emerging communication systems: Structural iconicity, interactive alignment and conventionalization. Cognition, 146, 6780.

Flaherty, M. (2014). The Emergence of Argument Structural Devices in Nicaraguan Sign Language (Doctoral Dissertation). Retrieved from Proquest.

Gibson, E., Piantadosi, S. T., Brink, K., Bergen, L., Lim, E., \& Saxe, R. (2013). A noisy-channel account of crosslinguistc word-order variation Psychological Science, 24(7), 1079-1088.

Goldin-Meadow, S., So, W. C., Ozyurek, A., \& Mylander, C. (2008). The natural order of events: How speakers of different languages represent events nonverbally. Proceedings of the National Academy of Sciences USA, 105(27), 9163-9168.

Schouwstra, M. \& de Swart, H. The semantic origins of word order. Cognition, 131(3), 431-436.

Schouwstra, M., Smith, K., \& Kirby, S. From natural order to convention in silent gesture. In The Evolution of Language: Proceedings of the $11^{\text {th }}$ International Conference (EVOLANG1 1). Roberts, S. G., Cuskley, C., McCrohon, L., Barceló-Coblijn, L., Fehrer, O. \& Verhoef, T. (eds). 